\title{
THE INFLUENCE OF DISTANCE ON Ultrasonic DENSITY MEASSUREMENTS
}

\author{
BERK, P.; RAKUn, J.; LAKOTA, M. \& MUSKINJA, N.
}

Abstract: In this work we describe how ultrasonic sensors can be used to detect tree canopies and their density, which correspond to the leaf quantity. In order to test the approach and estimate the best distance to be used for measurement, a test field was constructed and used in three test cases. The results show that the sensors are able to detect tree canopies in all examples, where the distance of $45 \mathrm{~cm}$ proved to be the best choice to measure the density of the tree canopy.

Key words: sensor, measuring, canopy, habitus
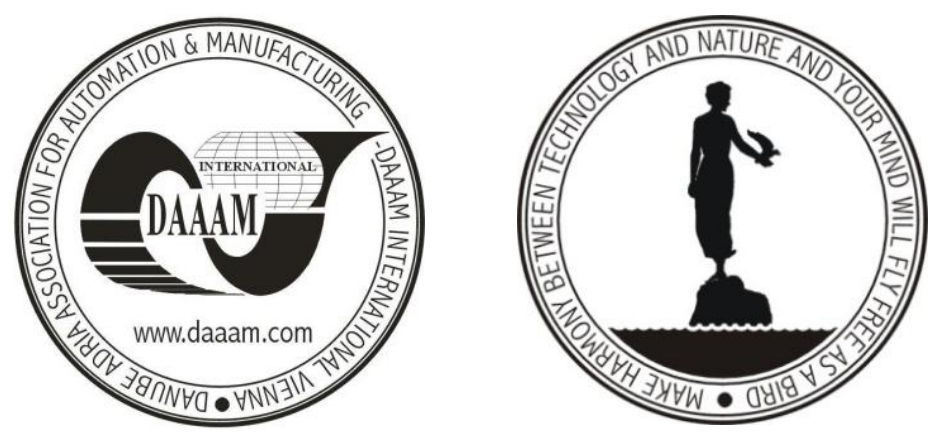

Authors' data: MSc. Berk, P[eter]*; Assist. Prof. Rakun, J[urij]*; Assoc. Prof. Lakota, M[iran]*; Assoc. Prof. Muskinja, N[enad]**, *University of Maribor, Faculty of Agriculture and Life Sciences, Pivola 10, SI-2311, Hoce, Slovenia, **University of Maribor, Faculty of Electrical Engineering and Computer Science, Smetanova ulica 17, SI-2000, Maribor, Slovenia, peter.berk@uni-mb.si, jurij.rakun@uni-mb.si,miran.lakota@uni-mb.si,nenad.muskinja@uni-mb.si

This Publication has to be referred as: Berk, P[eter]; Rakun, J[urij]; Lakota, M[iran] \& Muskinja, N[enad] (2013) The Influence of Distance on Ultrasonic Density Measurements, Chapter 36 in DAAAM International Scientific Book 2013, pp. 637-646, B. Katalinic \& Z. Tekic (Eds.), Published by DAAAM International, ISBN 978-3-901509-94-0, ISSN 1726-9687, Vienna, Austria DOI: 10.2507/daaam.scibook.2013.36 
Berk, P.; Rakun, J.; Lakota, M. \& Muskinja, N.: The Influence of Distance on Ultra...

\section{Introduction}

Precise definition of the trees and vine plants is one of the key factors that influences the selection of specific methods used to precisely apply pesticides in the apple orchards and vineyards. With the development of simple and effective methods we can to establish the parameters that serve to assist in identifying the structure of the tree canopy.

Various studies describe the use of ultrasonic sensors and LIDAR sensors (Llorens et al., 2011), where they are utilized ina process of measuring the volume and density of the tree canopy in apple orchards and vineyards. In both measurement methods the crucial value represents parameters related to the amount of trees, the width of each tree and its volume; are that is needed to assess the leaf surface in the habitus of the plantation. Published results show that ultrasonic sensors are suitable for determining the average characteristics of the trees, while the LIDAR sensor provides even higher precision and a more detailed view on the characteristics of the tree canopy. The studies found a good correlation between the ultrasonic sensors based measurement of the volume of the canopy measured against the leaf area index. Good correlation was also found between the estimated volume of the canopy, which was measured by the combination of ultrasonic and LIDAR sensors. Laser measurements were used to determine the density of the habitus while ultrasonic sensors were used to measure its height, enabling a precise calculation of the volume of the tree canopy. All described new approaches prove suitable and serve as an additional tool in improving the efficiency of application of pesticides, although they still needed further improvements to be commercially interesting.

Characteristics of a tree canopy habitus in orchards and vineyards can be measured manually. For this two simple measurements must be taken: an average plant height and crown width (Rüegg et al., 1999, Doruchowski et al., 2003,Viret et al., 2005). The total leaf area and leaf area index (LAI) can also manually measured. This includes destructive, time-consuming and expensive process that involves the entire defoliation (shedding) on the surface of the sample habitus and expanded laboratory measurements of each individual leaf area. It is also necessary to generalize the obtained values for the selected sampling area to the whole area of the trees without taking into account any deviation (variation) in the line of trees. An electronic measuring of the dimensions of the tree canopies is not a new concept. In papers (Giles et al., 1987, Giles et al., 1988), the authors discuss the use of ultrasonic sensors for measuring the volume of the crown of trees, peaches and apples, and use this information to improve the process of applying pesticides. The measuring system is based on three ultrasonic sensors, which were placed at different heights and placed on a special diffuser design. The next paper presents an improved method of the same authors (Giles et al., 1989), where they used an advanced algorithm to control the application of pesticides, where the results showed savings of pesticides in a range up to $52 \%$ in the apple orchard. 


\section{Ultrasonic Approach to Measure the Density of the Canopy}

In our work we used an ultrasonic module designed around a CYPRESS CY8C29466-24SXI microcontroller that has32 KB of Flash and $2 \mathrm{~KB}$ of Random Access Memory. Ultrasonic sensor with basic electronic circuit includes the built-in ultrasonic transmitter element, for which a PROWAVE 400EP250 transmitter was selected. The transmitter was connected to the microcontroller and uploaded acustom written firmware (Stajnko et al., 2012) developed in C language and PSoC Designer. The ultrasonic sensor is controlled by triggering the "Rx" line microcontroller with pulses that have a100 milliseconds width. When the sensor is triggered the transmitter of generates an ultrasonic pulse sent in direction of the tree canopy. When the ultrasonic signal is reflected from the canopy, receiving part of the transmitter receives the signal, which is then amplified by the FPGA electronic circuit of the microcontroller depicted in Fig. 1.The amplified signal is then time sampled and converted to a digital form. The sampled digitalized values correspond to the density of the tree canopies.

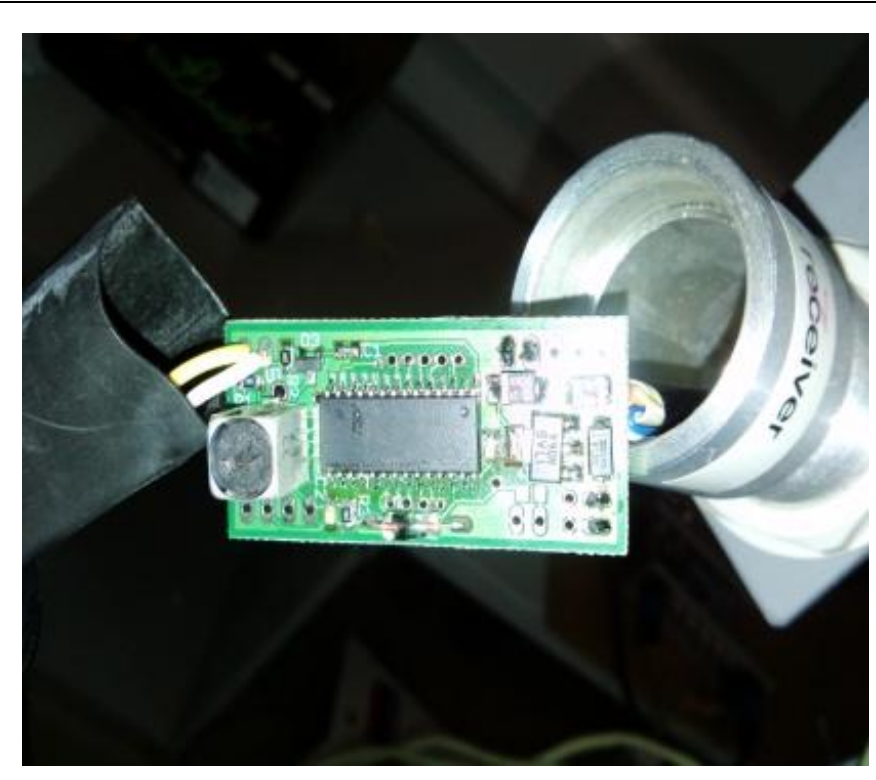

Fig. 1. The sensor circuit build around a PROWAVE 400EP250 transmitter and CYPRESS CY8C29466-24SXI FPGA microcontroller

The sensor communicates with the embedded computer and/or personal computer over the RS-232 interfaceat 57600 bits per second.

The ultrasonic sensors made up a sensor array, where the sensors are distributed according to their function; the centre sensor generates an ultrasonic burst, while the left and right serve as receiving sensors. Such distribution of sensors provides a highquality resolution data that is achieved with multiple sensors. They all take multiple measurements at the same time, but on different locations that correspond to different areas of the tree canopy. The distribution of sensors is shown in Fig. 2. 
Berk, P.; Rakun, J.; Lakota, M. \& Muskinja, N.: The Influence of Distance on Ultra...

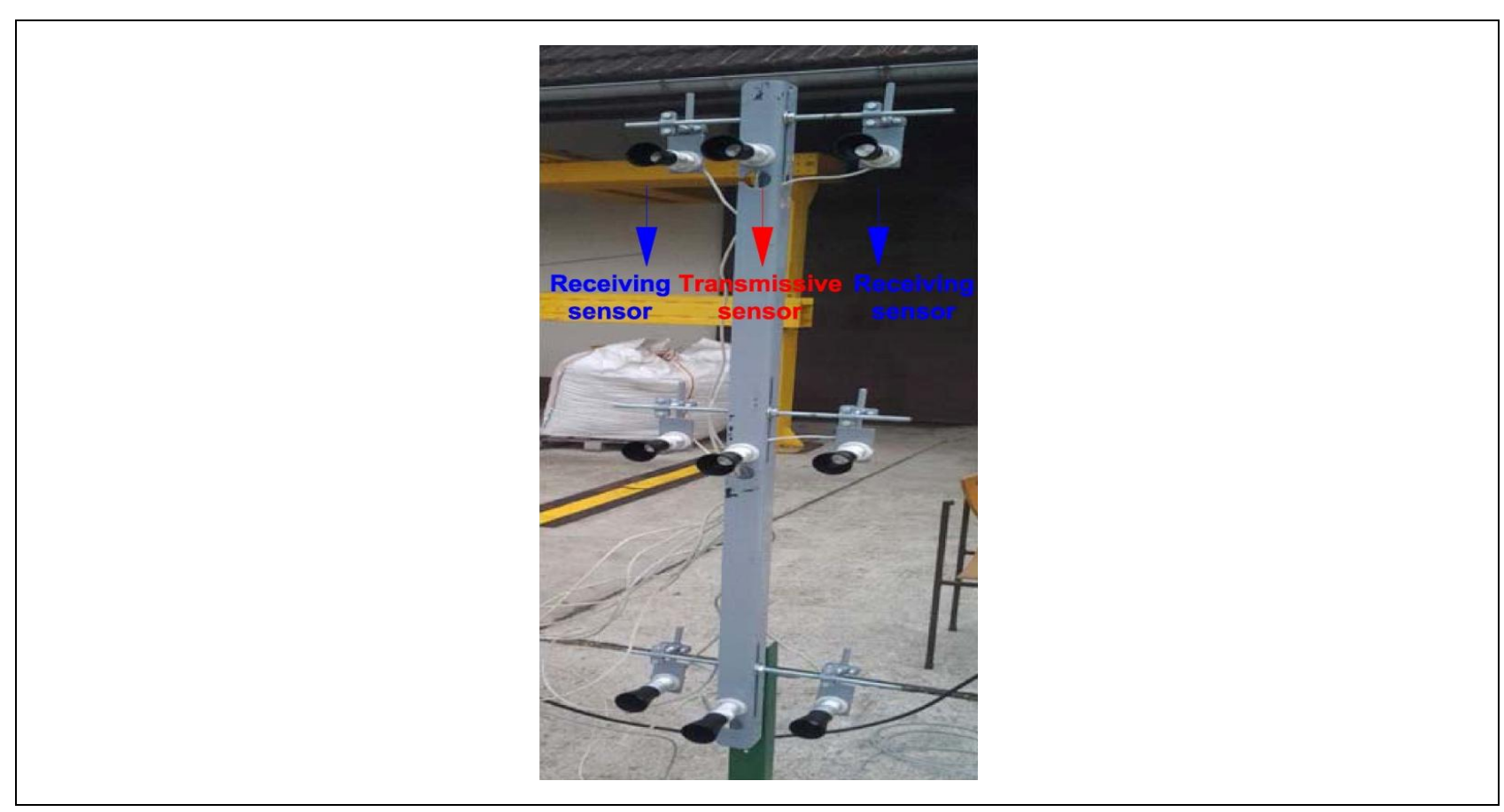

Fig. 2. The distribution of sensors; the middle three sensors generate an ultrasonic burst, while the left and right group receives it

The sensor array was mounted on a tractor and calibrated because each sensor is unique and can generate slightly $( \pm 5)$ lower or higher values then the average when detecting the same obstacle. Instead of using a moving tractor, test track was constructed, where the trees travelled in circles at $1 \mathrm{~m} / \mathrm{s}$ speed. They were measured by the sensor array, with the bottom three sensors positioned at $80 \mathrm{~cm}$, the second three at $133 \mathrm{~cm}$ an the upper three at $186 \mathrm{~cm}$.

The constructed test track is an oval shape and has $4 \mathrm{~m}$ long straight track on which simulations and measurements were conducted. The track can easily be extended with additional straight segments as it is shown in Fig. 3.

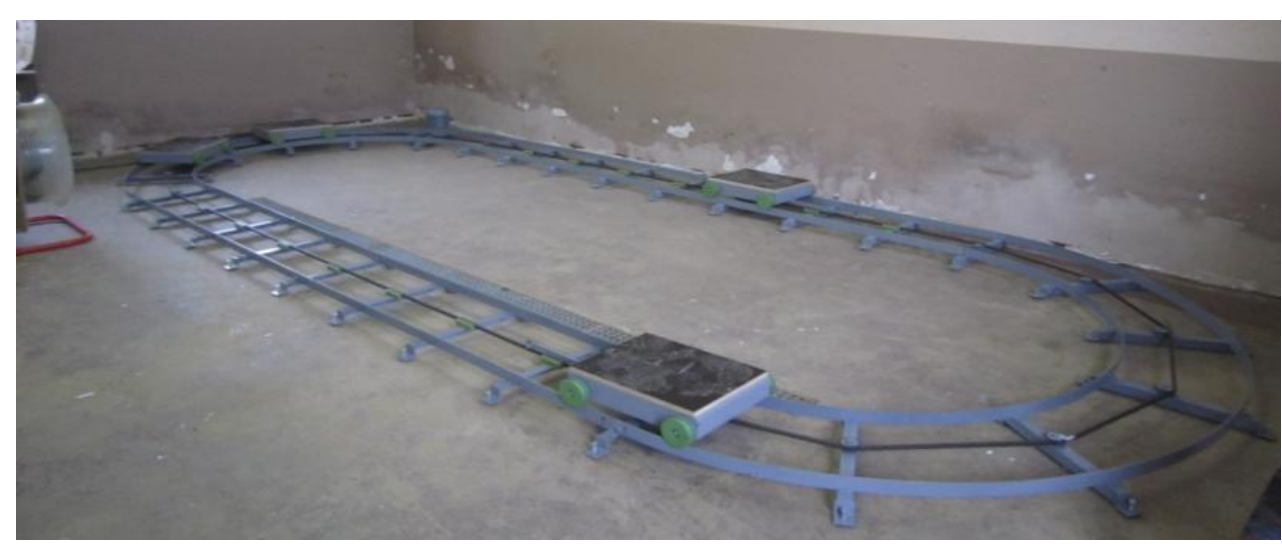

Fig. 3. Composite track for testing ultrasonic measurement system

Each segment of the trackis made up of two rails, which are secured with sleepers. Segments have a set of screws on the sides, which are used to level single segment independently of how even the surface is. Each straight segment also includes a lead to the drive chain and circular segments chairing, which allow 
movement of the chain in a curve. One of the circular segments includes a drive mechanism, which allows movement of the chain and via drawbars and pivots.

In order to pull the chain and make the trees move, a 3-phase electric motor was used that had to be connected to the track viaV-belt drive. With larger or smaller pulley an electric motor can roughly be configured to simulate a desired speed of the tree. To fine-tune the traveling speed a compact and powerful universal open-loop 3phase frequency regulator was used (Commander SKB 3400075). The regulator has $0.75 \mathrm{~kW}$ of power and is shown in Fig. 4 .

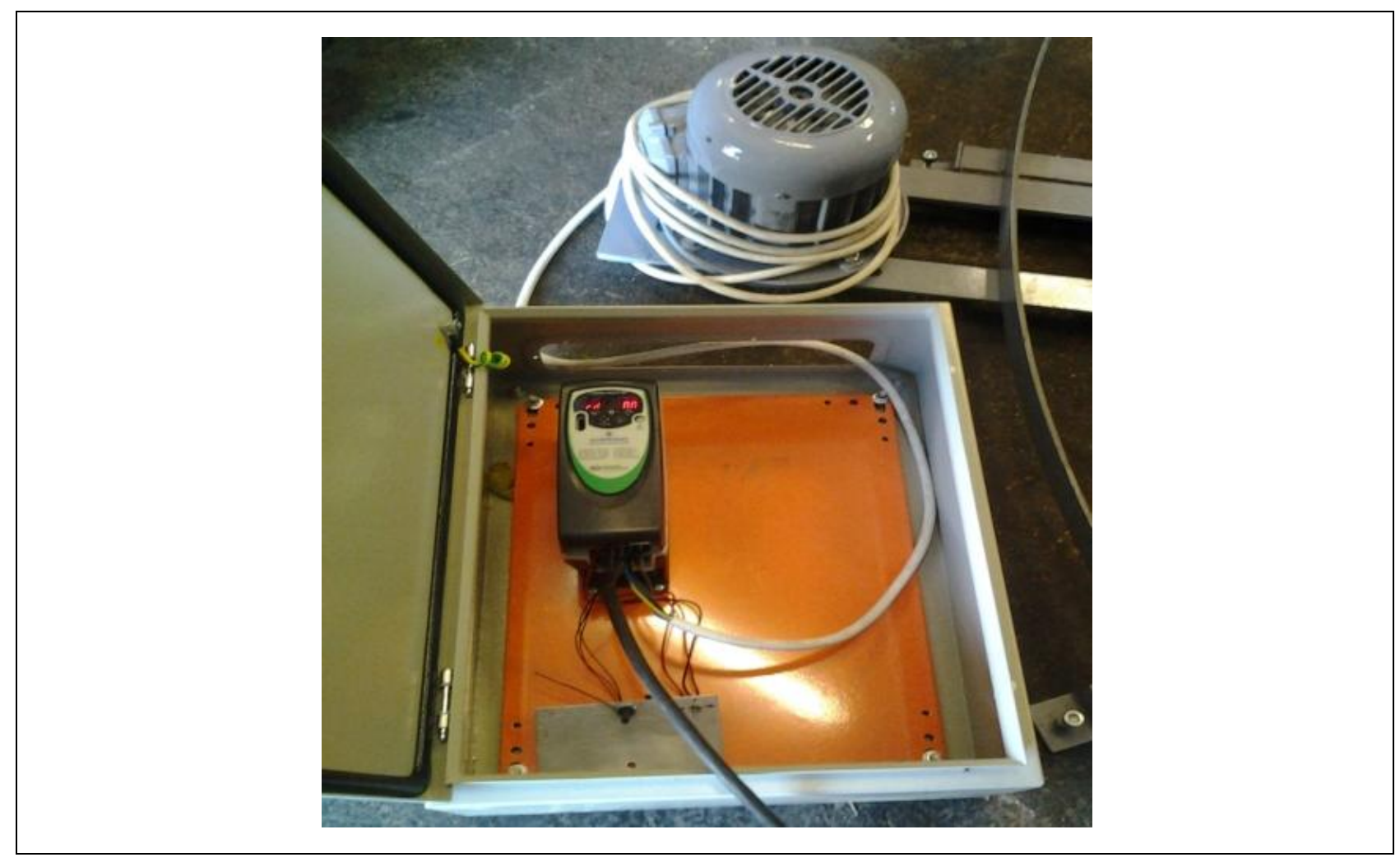

Fig. 4. Universal open-loop 3-phase frequency regulator that was used to fine-tune the traveling speeds

\section{Results}

In order to test the usefulness and the performance of the distance measuring ultrasonic sensor array, 3 test were conducted:

- the first with sensor array positioned $30 \mathrm{~cm}$ from the tree canopy,

- the second with sensor array positioned $45 \mathrm{~cm}$ from the tree canopy and

- the third with sensor array positioned $60 \mathrm{~cm}$ from the tree canopy.

In all three tests 10 successive runs were measured, where the tree canopy drove on the test tracks at $1 \mathrm{~m} / \mathrm{s}$ speed. Fig. 5 depicts the results of the two upper sensors positioned $30 \mathrm{~cm}$ from the canopy. 


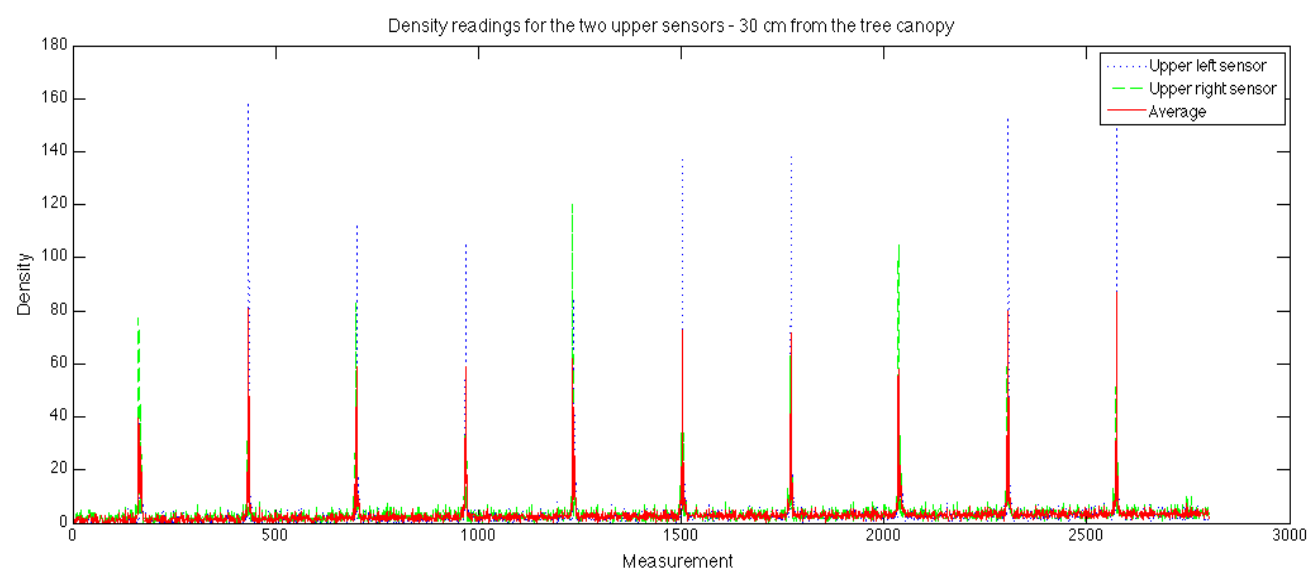

Fig. 5. Upper density readings of the tree canopy positioned $30 \mathrm{~cm}$ from the sensors

On average the readings were at $3.4 \pm 4.9$, with distinctive density measurements where the canopy was in front of the sensor. These measurements show up as peaks and that vary between 80 and 160, with average value of $21.8 \pm 19.3$. This is caused as the location where the sensors measure the density changes slightly from one canopy readings to the next.

The next figure summarizes the readings from the two middle sensors, positioned $30 \mathrm{~cm}$ from the tree canopy, with average readings of $1 \pm 5.6$. As in the Fig. 5 the readings in Fig. 6 show clear peaks with corresponding measurements when the tree canopy was just in front of the sensor. The density readings vary between 78and 145, with average peak value of $24 \pm 17.6$.

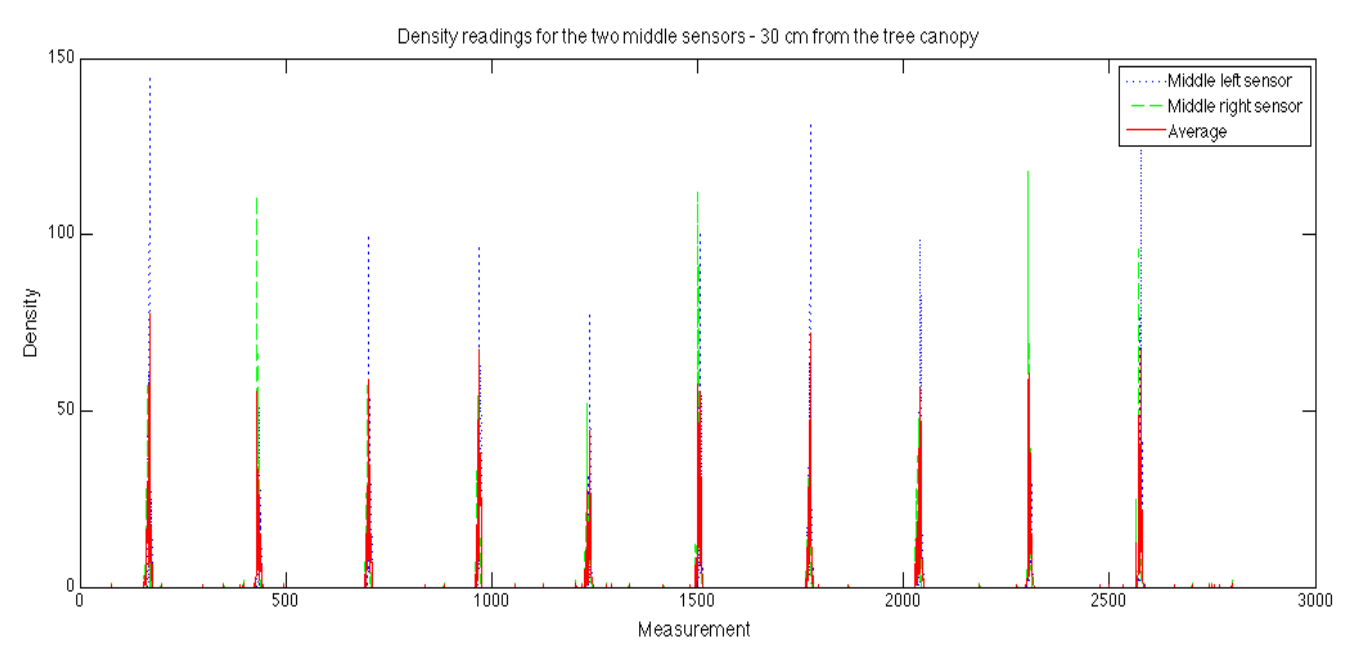

Fig. 6. Middle density readings of the tree canopy positioned $30 \mathrm{~cm}$ from the sensors

Fig. 7 shows tree canopy density measured with two lower sensors positioned 30 $\mathrm{cm}$ from the tree canopy, with average readings $1 \pm 2.9$. Again the peaks are clearly visible reaching on average of $15.8 \pm 11.2$. However, the peaks are in general lower then the peaks from Fig. 5 and Fig. 6 as the tree canopy is less dense in the lower part of the tree. 


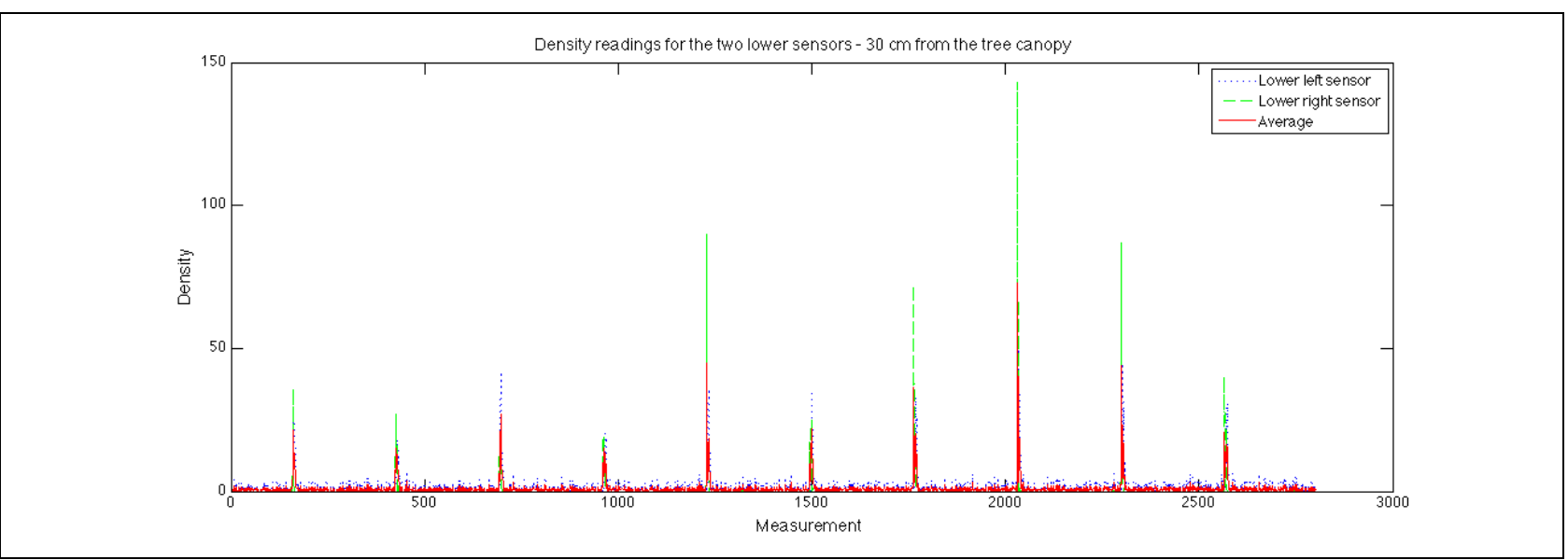

Fig. 7. Lower density readings of the tree canopy positioned $30 \mathrm{~cm}$ from the sensors

Fig. 8, 9 and 10 depict the second test run, with sensors array positioned $45 \mathrm{~cm}$ from the tree canopy. Density values for the upper sensors measure on average $8.4 \pm 3.4$ and $26.4 \pm 17.9$ for peaks, the middle $1.3 \pm 7.6$ and $40.4 \pm 20.5$ and the density from the lower sensors measures $3 \pm 20.6$ and $88.3 \pm 87.6$.

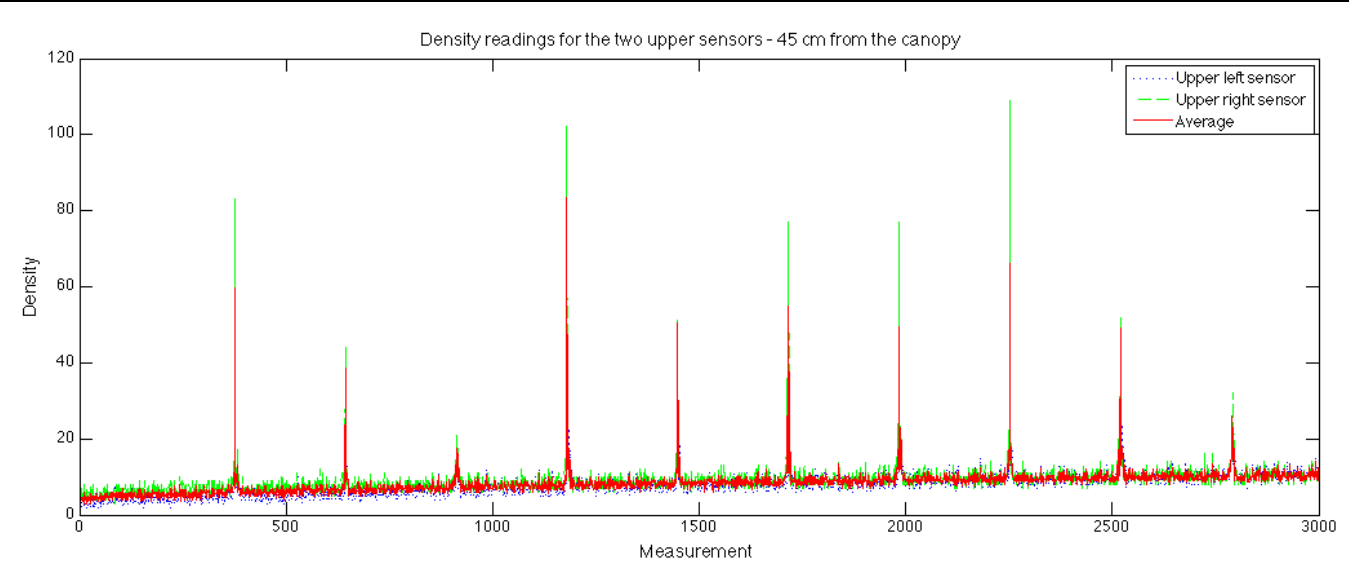

Fig. 8. Upper density readings of the tree canopy positioned $45 \mathrm{~cm}$ from the sensors

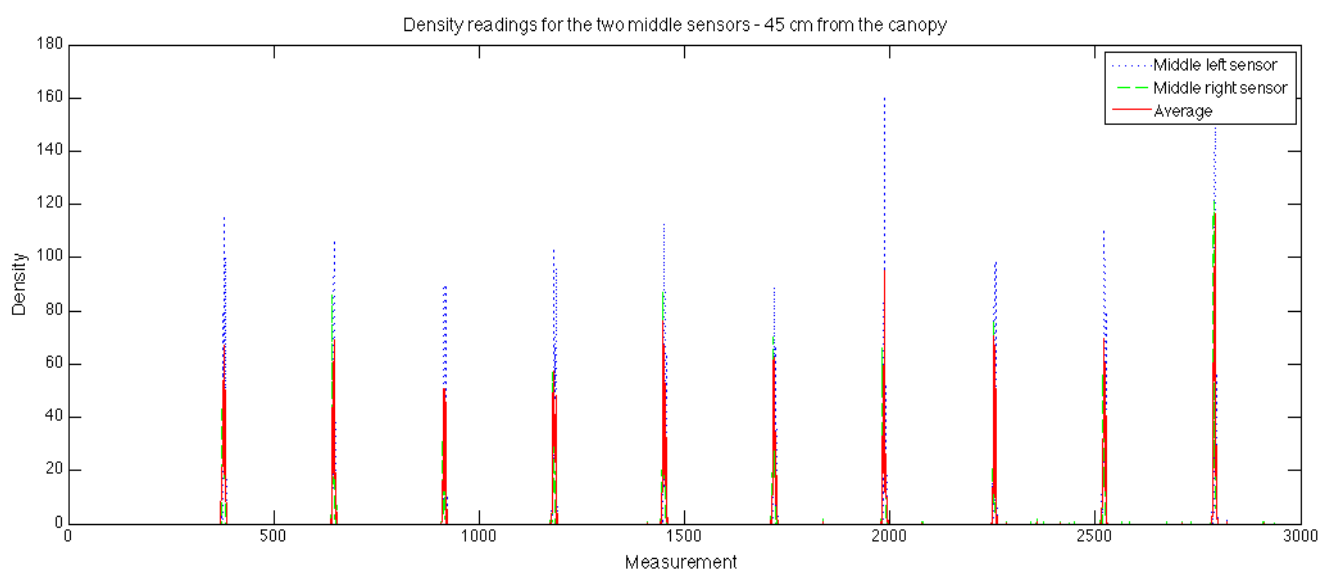

Fig. 9. Middle density readings of the tree canopy positioned $45 \mathrm{~cm}$ from the sensors 


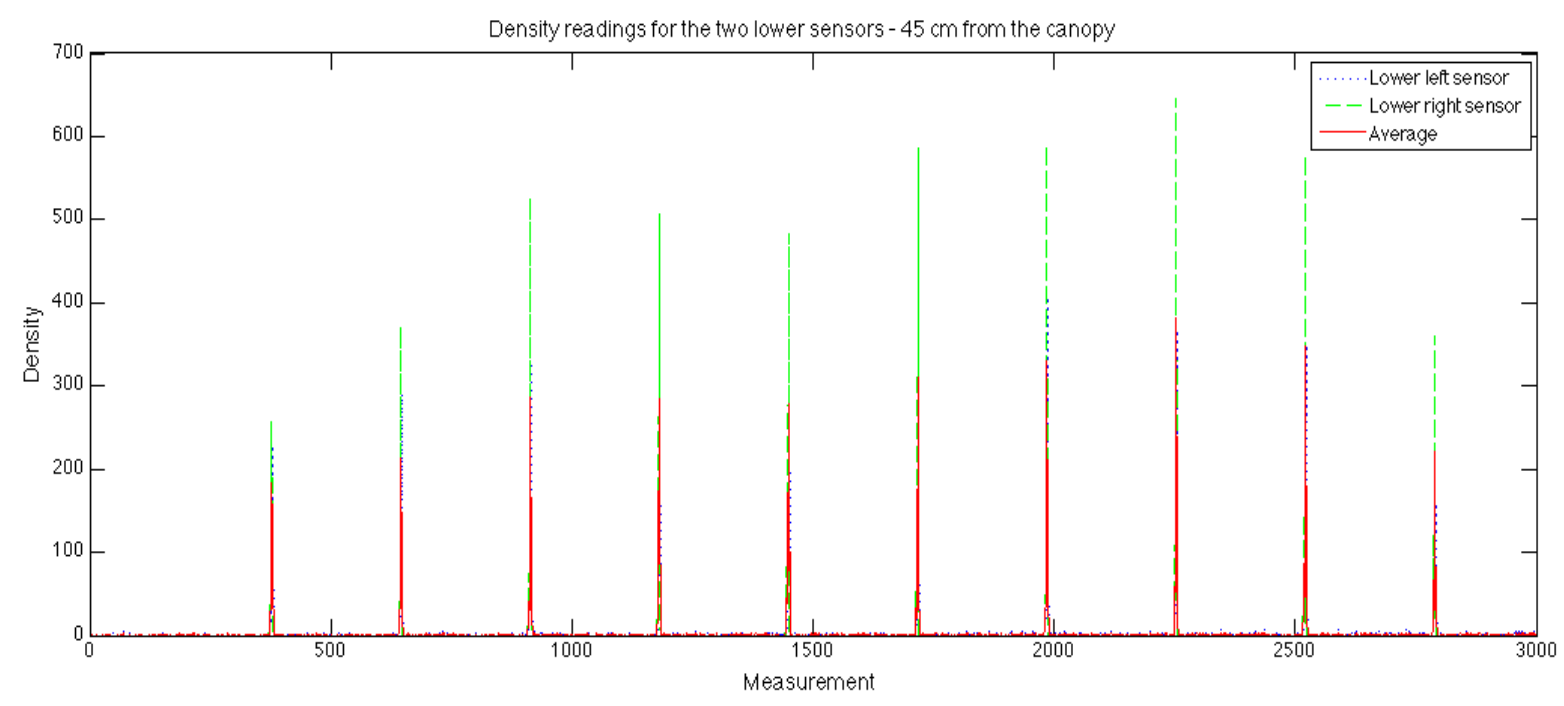

Fig. 10. Lower density readings of the tree canopy positioned $45 \mathrm{~cm}$ from the sensors

Based on the average overall and peak readings we can conclude that readings are higher than in the first test case as the ultrasound bounces back from bigger surface area on the canopy.

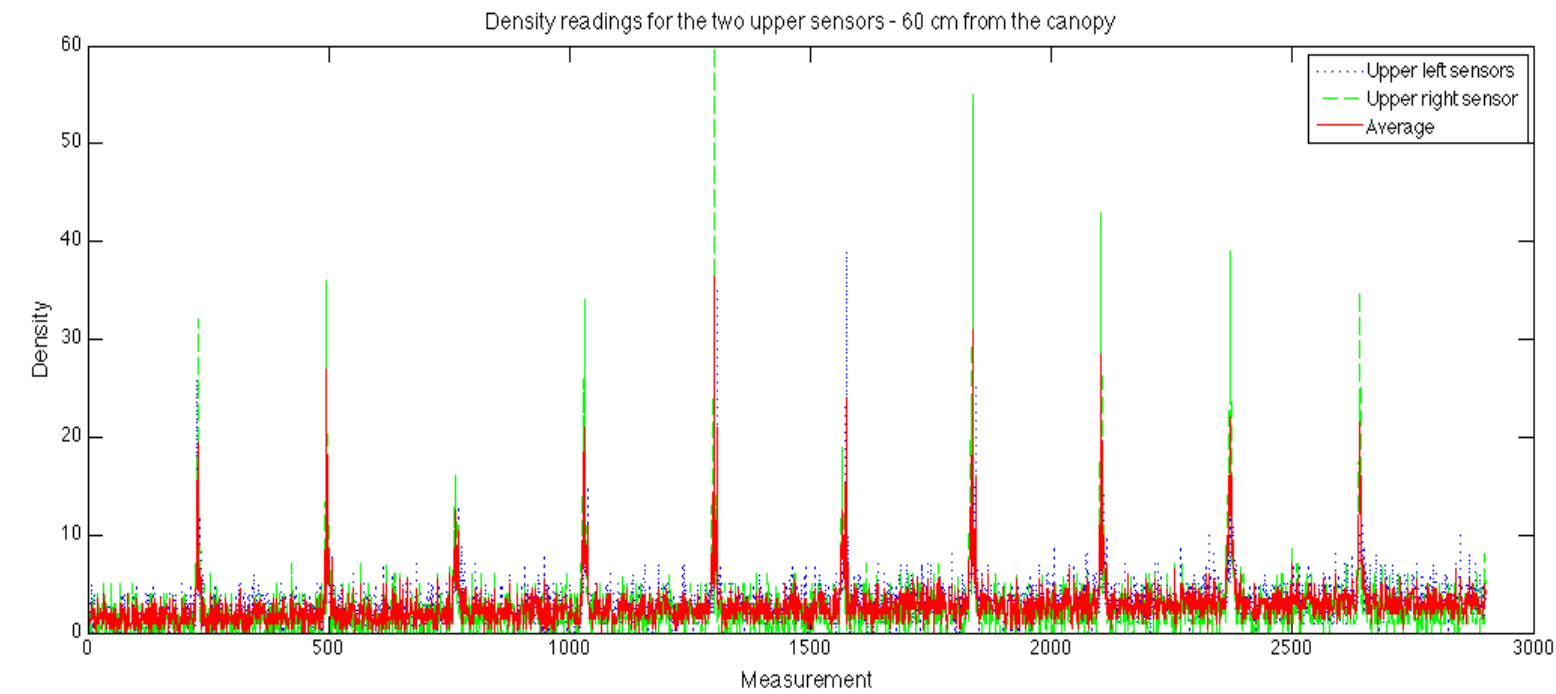

Fig. 11. Upper density readings of the tree canopy positioned $60 \mathrm{~cm}$ from the sensors

The last test case included density readings taken $60 \mathrm{~cm}$ from the sensor array. The readings are summarized on Fig. 11, 12 and 13. Once again distinctive peaks are detected. An overall averages and peak values were as follows: $2.8 \pm 2.3$ and $22.7 \pm 5.7$ for the upper sensors, $1.2 \pm 7.2$ and $38.6 \pm 23.3$ for the middle sensors and $2.1 \pm 6.8$ and $38.2 \pm 22.5$ for the lower sensors. 


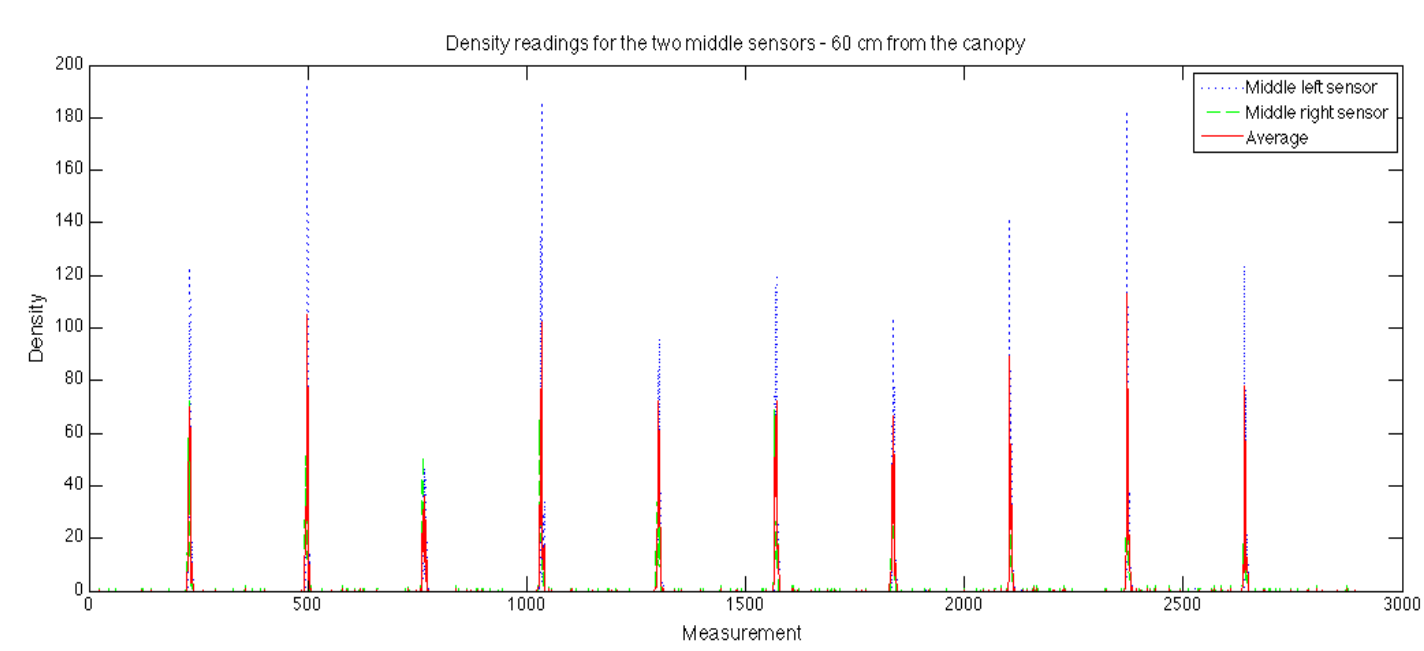

Fig. 12. Middle density readings of the tree canopy positioned $60 \mathrm{~cm}$ from the sensors

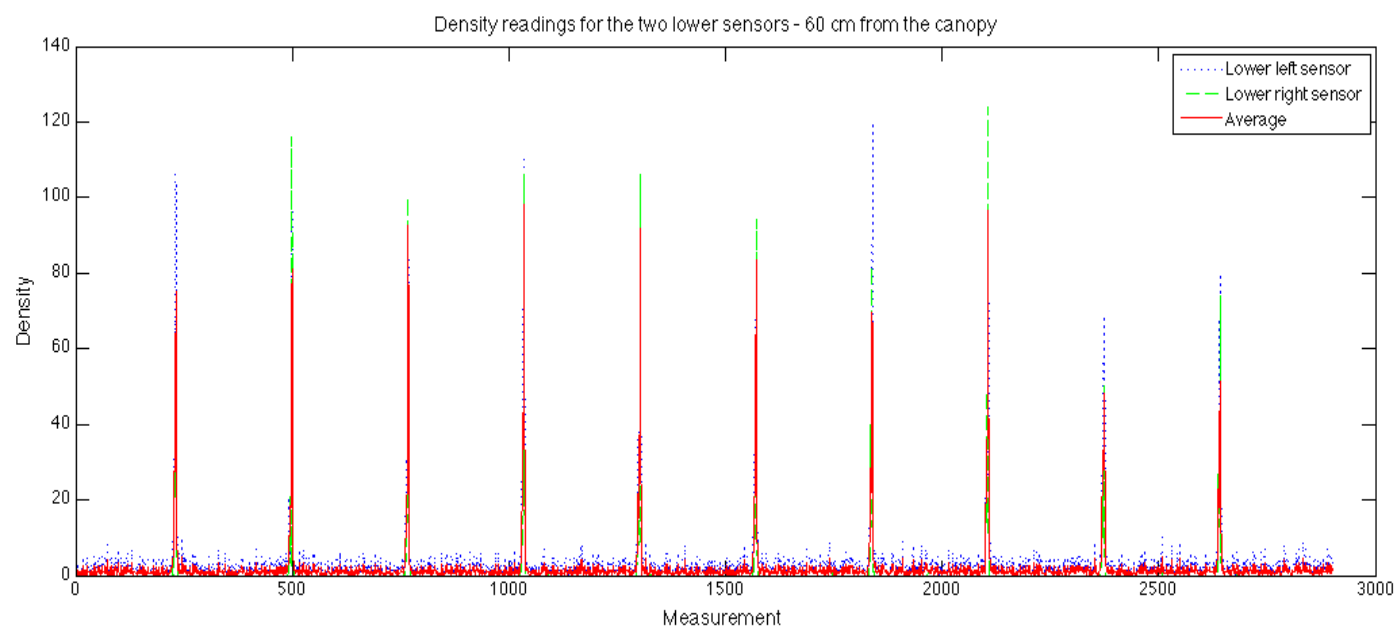

Fig. 13. Upper density readings of the tree canopy positioned $60 \mathrm{~cm}$ from the sensors

When comparing the third readings with the first and second, we can conclude, that they are higher than in the first test and similar or slightly lower then the second. This is normal as the ultrasound hits the whole area, as in the second test, but can also spread in other directions more and the sensor does not detect it.

Based on all three test cases we can conclude that the sensors do detect the tree canopy, or more precisely its density, which is not detected by other ultrasound solutions. Instead of measuringthe distance to the first obstacle, the ultrasound is sampled in chronologicalorder that reveals the thickness of the canopy at each depth.

The quantity (summed reflections) of the reflected ultrasound show up as a distinct values which are suitable to be used as an indicator of a tree canopy. From all three test cases the $45 \mathrm{~cm}$ distance proved to be the best choice as the ultrasound is reflected from the whole surface area of the canopy, while it is still possible to collect most of the reflected ultrasound. 
Berk, P.; Rakun, J.; Lakota, M. \& Muskinja, N.: The Influence of Distance on Ultra...

\section{Conclusion}

In this work we have presented how to detect tree canopies using ultrasonic sensors. In comparison to other kinds of sensors ultrasonic sensors are cheep and therefore more accessible to wider range of users. The use of ultrasonic sensors is also appealing when it comes to pesticide application. It offers both economical as well as ecological advantages; it minimises the use of pesticides on only selective areas, where it should be sprayed, and it reduces its usage on other areas where it is not needed and might even cause potential health problems if it is accumulated over time.

By analysing 90 measurements of the same tree canopy, we have selected the optimal distance to be used when estimating density of the canopy with ultrasonic sensors. These 90 measurements were part of three test cases where it was proven that they are useful when trying to detect tree canopies.

Furthermore, the readings from the sensor offer a numeric estimate of the tree canopy thickness, which can be used to adjust the flow of pesticides. In our upcoming studies we will investigate two possible solutions that would further improve the system. One possible solution is to use support vector machines to estimate the optimal thresholds and the other the use of fuzzy logic to solve the non-linear problem that involves the readings from multiple sensors and how/how much to open each valve.

\section{References}

Doruchowski, G.; Bielenin, A.; Holownicki, R.; Swiechowski, W.; Godyn, A. \& Olszak, R.W. (2003). Efficacy of TRV Based Fungicide Dose Rates in Apple Orchards, In VII Workshop on Spray Application Techniques in Fruit Growing, Cuneo, Italy, pp 157-162 Giles, D.K.; Delwiche, M.J. \& Dodd, R.B. (1987). Control of Orchard Spraying Based on Electronic Sensing of Target Characteristics, Trans. ASAE, vol. 30, pp 1624-1630

Giles, D.K.; Delwiche, M.J. \& Dodd, R.B. (1988). Electronic Measurement of Tree Canopy Volume, Trans. ASAE, vol. 31, pp 264-272

Giles, D.K.; Delwiche, M.J. \& Dodd, R.B. (1989). Method and Appar at us for Target Plant Foliage Sensing and Mapping and Related Materials Application Control, U.S. Patent, vol. 4

Giles, D.K.; Delwiche, M.J. \& Dodd, R.B. (1989). Sprayer Control by Sensing Orchard Crop Characteristics: Orchard Architecture and Spray Liquid Savings, J. Agric. Eng. Res., vol. 43, pp 271-289

Llorens, J.; Gil, E.; Llop J. \& Escolà, A. (2011). Ultrasonic and LIDAR Sensors for Electronic Canopy Characterization in Vineyards: Advances to Improve Pesticide Application Methods, Sensors, vol. 11, pp 2177-2194

Rüegg, J.; Viret, O. \& Raisigl, U. (1999). Adaptation of Spray Dosage in Stone-Fruit Orchards on the Basis of Tree Row Volume, EPPO Bull.,vol. 29, pp 103-110

Stajnko, D.; Berk, P.; Lešnik, M.; Jejčič, V.; Lakota, M.; Štrancar, A.; Hočevar, M. \& Rakun, J. (2012). Programmable ultrasonic sensing system for targeted spraying in orchards, Sensors, vol. 12, pp 15500-15519

Viret, O.; Siegfried, W.; Wohlhauser, R. \& Raisigl, U. (2005). Dosage Des Fongicides En Fonction Du Volume Foliaire De La Vigne, Rev. Suisse Vitic. Arboric. Hortic., vol. 37, pp 59-62 